\title{
Synthesis of Fluorine-containing Poly(acetal)s by the Polyaddition of Bisphenol AF with Divinyl Ether Compounds and Their Photoinduced Depolymerization
}

\author{
Yousuke Konno, Kazuaki Matsumura, Hiroto Kudo, \\ Atsushi KAMEYAMA, and Tadatomi NishiKUBO ${ }^{\dagger}$ \\ Department of Applied Chemistry, Faculty of Engineering, Kanagawa University, \\ 3-27-1 Rokkakubashi, Kanagawa-ku, Yokohama 221-8686, Japan
}

(Received January 26, 2004; Accepted May 1, 2004; Published July 15, 2004)

\begin{abstract}
Fluorine-containing poly(acetal)s were synthesized by the polyaddition of bisphenol AF (BPAF) with divinyl ether compounds. It was found that the poly(acetal) (PA-1) with a number average molecular weights of 4400 was obtained in $71 \%$ yield by the polyaddition of BPAF with ethylene glycol divinyl ether (EGDVE) using $1 \mathrm{~mol} \%$ of pyridinium $p$-toluene sulfonate (PTS) as a catalyst in THF at room temperature for $24 \mathrm{~h}$. Furthermore, the polyaddition of BPAF with other divinyl ether compounds were also carried out to give corresponding poly(acetal)s (PA-2-PA-3) in appropriate reaction conditions. It was also found that the photoinduced depolymerization of the resulting poly(acetal)s proceeded using photo-acid generator (PAG) by the photo-irradiation in the film state. It was found that transmittance of PA-1 was 39\% at $157 \mathrm{~nm}$ for $0.1 \mu \mathrm{m}$ thickness. [DOI 10.1295/polymj.36.531]

KEY WORDS Fluorine-containing Poly(acetal) / Divinyl Ether Compound / Polyaddition / Photoinduced Depolymerization / Photoresist /
\end{abstract}

Semiconductor device manufacture has been supported with the photolithography technology. Development of photolithography technology has made possible the high resolution and high performance of a semiconductor device. Therefore, the new photolithography technology requires the development of new photoresist materials.

Recently, the vacuum ultraviolet (VUV) lithography using $\mathrm{F}_{2}$ excimer laser with a wavelength of $157 \mathrm{~nm}$ is expected as the next generation lithography technology. Photoresist materials for VUV lithography must be high transparent at $157 \mathrm{~nm}$. Fluorinated polymers and silsesquioxane polymers are fairly transparent in the VUV regions. Recently, many research groups investigated on developing $157 \mathrm{~nm}$ photoresists based on fluorinated polymers. ${ }^{1-6}$ Willson et $a l .{ }^{7}$ described that the approach to the design of the resist materials requires identification of four modules: backbone, etch barrier, acidic group, and acid labile protecting group. These modules must be high transparent at $157 \mathrm{~nm}$. Ober et al. ${ }^{2}$ focused on acetal groups as transparent protecting groups of acidic module. Because, it is useful as protecting groups for $157 \mathrm{~nm}$ resist that acetal groups have high reactivity to the photo-produced acids in the chemically amplification system. Meanwhile, Zhang and Ruckenstein ${ }^{8}$ reported recently the synthesis of poly(acetal)s by the polyaddition of bisphenol A with divinyl ether compounds using pyridinium $p$-toluene sulfonate (PTS) as a cata- lyst. These polymers have been expected as recyclable polymers. Ueda and co-workers ${ }^{5}$ reported an interesting polymer, poly(methyl vinyl sulfonate), which showed excellent transparency at $157 \mathrm{~nm}$ as suggested by the theoretical calculation.

We previously reported the polyaddition of fluorine-containing bis(epoxide) $\mathrm{s}^{9}$ or bis(oxetane) $\mathrm{s}^{10}$ with fluorine-containing diols to produce corresponding fluorine-containing poly(ether)s with pendant hydroxyl groups. These polymers were highly transparent at $157 \mathrm{~nm}$. On the above results, it was also found that fluorine-containing diols such as bisphenol $\mathrm{AF}$ (BPAF) exhibited highly transparent at $157 \mathrm{~nm}$ and excellent thermal properties.

In this article, we examined the synthesis of fluorine-containing poly(acetal)s by the polyaddition of BPAF with divinyl ether compounds. Furthermore, we investigated on the photoinduced depolymerization of resulting fluorine-containing poly(acetal)s.

\section{EXPERIMENTAL}

\section{Materials}

Solvents were dried using $\mathrm{P}_{2} \mathrm{O}_{5}, \mathrm{CaH}_{2}$, or Na metal wire, and purified in the usual way before use. Tetrabutylammonium bromide (TBAB) was recrystallized twice from ethyl acetate. Reagent grades of pyridinium $p$-toluenesulufonate (PTS), potassium hydroxide $(\mathrm{KOH})$, potassium tert-butoxide $(t-\mathrm{BuOK})$ were used

†To whom correspondence should be addressed (E-mail: nishit02@kanagawa-u.ac.jp). 
without further purification. 2,2-Bis(4-hydoroxyphenyl)hexafluoropropane (BPAF) was purified by sublimation. Ethylene glycol divinyl ether (EGDVE), 1,4-cyclohexane dimethanol divinyl ether (HMDVE) and 1,2-dibromoethane was used without further purification. Photo-acid generator such as bis-[4-(diphenylsulfonio)phenyl]sulfide bis(hexafluorophosphate) (DPSP; Degussa) was also used without further purification.

\section{Measurements}

Infrared (IR) spectra were measured on a Jasco Model IR-420 spectrometer. The ${ }^{1} \mathrm{H}$ NMR spectra were recorded on JEOL Model JNM $\alpha-500$ $\left(500 \mathrm{MHz}\right.$ for ${ }^{1} \mathrm{H} \mathrm{NMR}, 125 \mathrm{MHz}$ for ${ }^{13} \mathrm{C} \mathrm{NMR}$, $470 \mathrm{MHz}$ for ${ }^{19} \mathrm{~F} \mathrm{NMR}$ ) instruments in $\mathrm{CDCl}_{3}$ or DMSO- $d_{6}$ using $\mathrm{Me}_{4} \mathrm{Si}$ (TMS) for ${ }^{1} \mathrm{H}$ NMR and $\mathrm{C}_{6} \mathrm{~F}_{6}$ for ${ }^{19} \mathrm{~F}$ NMR as an internal standard. The numberaverage molecular weights $\left(M_{\mathrm{n}}\right)$ and molecular weight distributions $\left(M_{\mathrm{w}} / M_{\mathrm{n}}\right)$ of the polymers were estimated by gel permeation chromatography (GPC) with the use of a Tosoh model HLC-8120 GPC equipped with refractive index and ultraviolet detectors using TSK gel columns (eluent THF, calibrated with narrow molecular weight polystyrene standards). The $T_{\mathrm{g}} \mathrm{s}$ of the polymers were measured on a Seiko Instruments differential scanning calorimeter (DSC) Model EXSTAR6000/DSC6200 at a heating rate of $10^{\circ} \mathrm{C} /$ min under nitrogen. The thermal analysis was performed on a Seiko Instruments thermogravimetric analysis (TGA) Model EXSTAR6000/TG/DTA6200 at a heating rate of $10^{\circ} \mathrm{C} / \mathrm{min}$ under nitrogen. Vacuum ultraviolet (VUV) spectra were recorded on a Jasco Model VU-201.

Synthesis of 2,2-Bis[4-(2-Bromoethyloxy)phenyl]hexafluoropropane (BPAFBE)

An NMP $(30 \mathrm{~mL})$ solution of BPAF $(10.1 \mathrm{~g}, 30$ $\mathrm{mmol}), \mathrm{KOH}(10.1 \mathrm{~g}, 120 \mathrm{mmol})$ as a base, and TBAB (97 mg, $5.0 \mathrm{~mol} \%$ ) was stirred at room temperature for $2 \mathrm{~h}$. Then, 1,2-dibromoethane $(112.8 \mathrm{~g}, 600 \mathrm{mmol})$ was added to the solution, and the mixture was stirred for $48 \mathrm{~h}$ at the same temperature. The reaction mixture was diluted with ethyl acetate, washed three times with water, and dried with anhydrous $\mathrm{MgSO}_{4}$. Solvent was evaporated, and then crude product was purified by silica gel column chromatography with ethyl acetate/n-hexane $(1 / 2)$ as an eluent. The yield of BPAFBE was $11.8 \mathrm{~g}(67 \%)$.

IR (neat, $\left.\mathrm{cm}^{-1}\right): 2934,2865(\nu \mathrm{C}-\mathrm{H}), 1612,1515$ $(\nu \mathrm{C}=\mathrm{C}$, aromatic $), 1254,1173(\nu \mathrm{C}-\mathrm{F}), 1130(\nu \mathrm{C}-\mathrm{O}-$ $\mathrm{C}$, ether), $573(\nu \mathrm{C}-\mathrm{Br}) .{ }^{1} \mathrm{H} \mathrm{NMR}\left(200 \mathrm{MHz}, \mathrm{CDCl}_{3}\right.$, TMS): $\delta 3.65\left(\mathrm{t}, J=6.0 \mathrm{~Hz}, 4.0 \mathrm{H}, \mathrm{CH}_{2} \mathrm{CH}_{2}-\mathrm{Br}\right)$, $4.31\left(\mathrm{t}, J=6.0 \mathrm{~Hz}, 4.0 \mathrm{H}, \mathrm{CH}_{2} \mathrm{CH}_{2}-\mathrm{Br}\right.$ ), $6.89-7.31$ (m, 8.0H, aromatic $\mathrm{H})$.
Synthesis of 2,2-Bis(4-vinyloxyphenyl)hexafluoropropane (BPAFVE)

The mixture of BPAFBE $(11.0 \mathrm{~g}, 20 \mathrm{mmol})$ and $t$ BuOK $(5.4 \mathrm{~g}, 48 \mathrm{mmol})$ in NMP $(20 \mathrm{~mL})$ was stirred at $80^{\circ} \mathrm{C}$ for $2 \mathrm{~h}$. The reaction mixture was diluted in ethyl acetate, washed three times with water, and dried with anhydrous $\mathrm{MgSO}_{4}$. Solvent was evaporated, and then crude product was purified by alumina column chromatography with ethyl acetate $/ n$-hexane $(1 / 20)$ as an eluent. The yield of BPAFVE was $3.8 \mathrm{~g}$ $(48 \%)$.

IR (neat, $\left.\mathrm{cm}^{-1}\right): 3069,3053(\nu \mathrm{C}-\mathrm{H}), 1647(\nu \mathrm{C}=\mathrm{C}$, vinyl), 1607, $1512(\nu \mathrm{C}=\mathrm{C}$, aromatic $), 1251,1175$ ( $\nu \mathrm{C}-\mathrm{F}), 1130\left(\nu \mathrm{C}-\mathrm{O}-\mathrm{C}\right.$, ether). ${ }^{1} \mathrm{H}$ NMR $(500 \mathrm{MHz}$, $\left.\mathrm{CDCl}_{3}, \mathrm{TMS}\right): \delta 4.53(\mathrm{dd}, J=1.5,13.7 \mathrm{~Hz}, 2.0 \mathrm{H}$, $\mathrm{CH}_{2}$ in vinyl), $4.86\left(\mathrm{dd}, J=1.5,5.9 \mathrm{~Hz}, 2.0 \mathrm{H}, \mathrm{CH}_{2}\right.$ in vinyl), $6.66(\mathrm{dd}, J=5.9,13.7 \mathrm{~Hz}, 2.0 \mathrm{H}, \mathrm{CH}$ in vinyl), $6.99(\mathrm{~d}, J=9.0 \mathrm{~Hz}, 4.0 \mathrm{H}$, aromatic $\mathrm{H}), 7.34(\mathrm{~d}$, $J=9.0 \mathrm{~Hz}, 4.0 \mathrm{H}$, aromatic $\mathrm{H}) .{ }^{13} \mathrm{C}$ NMR $(125 \mathrm{MHz}$, DMSO- $\left.d_{6}, \mathrm{TMS}\right): \delta 63.7(\mathrm{C}), 96.7\left(\mathrm{CH}_{2}=\right), 124.2$ $\left(\mathrm{q}, J=285.9 \mathrm{~Hz}, \mathrm{CF}_{3}\right), 147.1$ (=CH-), 116.3, 127.7, 131.7, 157.1 (aromatic C). ${ }^{19} \mathrm{~F}$ NMR $(470 \mathrm{MHz}$, DMSO- $\left.d_{6}, \mathrm{C}_{6} \mathrm{~F}_{6}\right): \delta-66.8\left(\mathrm{~s}, \mathrm{CF}_{3}\right)$.

Typical Procedure for the Synthesis of PA-1 by the Polyaddition of BPAF with EGDVE

A typical procedure for polyaddition of BPAF with EGDVE was as follows: BPAF (168.1 $\mathrm{mg}, 0.5 \mathrm{mmol})$, EGDVE $(57.1 \mathrm{mg}, \quad 0.5 \mathrm{mmol})$, PTS $(2.5 \mathrm{mg}, \quad 1.0$ $\mathrm{mol} \%)$ as a catalyst, and THF $(0.5 \mathrm{~mL}, 1 \mathrm{~mol} / \mathrm{L})$ as a solvent were charged into a flask. The reaction was performed at room temperature for $24 \mathrm{~h}$ under stirring. The reaction mixture was diluted in ethyl acetate, washed three times with aq. $1 \mathrm{~N} \mathrm{NaOH}$, and once with water, and dried with anhydrous $\mathrm{MgSO}_{4}$. The solvent was evaporated, and then the resulting polymer was reprecipitated from THF into $n$-hexane, and dried in vacuo. The yield of resulting polymer (PA1) was $132.6 \mathrm{mg}(59 \%)$. The number-average molecular weight $\left(M_{\mathrm{n}}\right)$ of the polymer determined by GPC was $3500\left(M_{\mathrm{w}} / M_{\mathrm{n}}=2.19\right)$. IR (film, $\left.\mathrm{cm}^{-1}\right): 3328$ $(\nu \mathrm{O}-\mathrm{H}), \quad 2990,2939,2879 \quad(\nu \mathrm{C}-\mathrm{H}), \quad 1612,1514$ $(\nu \mathrm{C}=\mathrm{C}$, aromatic $), 1249,1172(\nu \mathrm{C}-\mathrm{F}), 1206,1132$, 1078 ( $\nu \mathrm{C}-\mathrm{O}-\mathrm{C}$, acetal). ${ }^{1} \mathrm{H} \mathrm{NMR} \quad(500 \mathrm{MHz}$, DMSO- $d_{6}$, TMS $): \delta 1.46(\mathrm{~d}, J=6.0 \mathrm{~Hz}, 6.0 \mathrm{H}$, $\left.\mathrm{CH}_{3}\right), 3.61-3.79\left(\mathrm{~m}, 4.0 \mathrm{H}, \mathrm{CH}_{2}\right), 5.41-5.48(\mathrm{~m}$, $2.0 \mathrm{H}, \mathrm{CH}), 6.77-6.93(\mathrm{~m}, 4.0 \mathrm{H}$, aromatic $\mathrm{H}), 7.24-$ $7.28\left(\mathrm{~m}, 4.0 \mathrm{H}\right.$, aromatic H). ${ }^{19} \mathrm{~F}$ NMR $(470 \mathrm{MHz}$, DMSO- $\left.d_{6}, \mathrm{C}_{6} \mathrm{~F}_{6}\right): \delta-62.9$ to $-63.0\left(\mathrm{~m}, \mathrm{CF}_{3}\right)$.

Synthesis of PA-2 by the Polyaddition of BPAF with HMDVE

The reaction was carried out with BPAF $(168.1 \mathrm{mg}$, $0.5 \mathrm{mmol}$ ) and HMDVE (98.1 $\mathrm{mg}, 0.5 \mathrm{mmol})$ using PTS $(2.5 \mathrm{mg}, 1.0 \mathrm{~mol} \%)$ as a catalyst in THF 
$(0.5 \mathrm{~mL}, 1.0 \mathrm{~mol} / \mathrm{L})$ at room temperature for $24 \mathrm{~h}$. The yield of PA-2 was $160.8 \mathrm{~g}(60 \%)$. The $M_{\mathrm{n}}$ of the PA-2 determined by GPC was $8400\left(M_{\mathrm{w}} / M_{\mathrm{n}}=1.45\right)$. IR (film, $\left.\mathrm{cm}^{-1}\right): 3328(\nu \mathrm{O}-\mathrm{H}), 2988,2920,2858(\nu \mathrm{C}-$ $\mathrm{H}), 1611,1512(\mathrm{v}=\mathrm{C}$, aromatic $), 1251,1173(\nu \mathrm{C}-$ F), 1206, 1132, 1073 (vC-O-C, acetal). ${ }^{1} \mathrm{H}$ NMR (500 MHz, DMSO- $d_{6}$, TMS): $\delta 0.91-1.86(\mathrm{~m}, 16.0 \mathrm{H}$, $\mathrm{CH}, \mathrm{CH}_{2}$ in cyclohexane ring, $\left.\mathrm{CH}_{3}\right), 3.27-3.55(\mathrm{~m}$, $\left.4.0 \mathrm{H}, \mathrm{CH}_{2}\right), 5.23-5.41(\mathrm{~m}, 2.0 \mathrm{H}, \mathrm{CH}), 6.94-6.96(\mathrm{~m}$, 4.0H, aromatic $\mathrm{H}), 7.26-7.29(\mathrm{~m}, 4.0 \mathrm{H}$, aromatic $\mathrm{H})$. ${ }^{19} \mathrm{~F}$ NMR $\left(470 \mathrm{MHz}, \mathrm{DMSO}-d_{6}, \mathrm{C}_{6} \mathrm{~F}_{6}\right): \delta-62.9$ to $-63.0\left(\mathrm{~m}, \mathrm{CF}_{3}\right)$.

Synthesis of PA-3 by the Polyaddition of BPAF with $B P A F V E$

PA-3 was synthesized by the polyaddition of BPAF (168.1 mg, $0.5 \mathrm{mmol}$ ) with BPAFVE (194.2 mg, $0.5 \mathrm{mmol})$ using PTS $(2.5 \mathrm{mg}, 1.0 \mathrm{~mol} \%)$ as a catalyst in THF $(0.5 \mathrm{~mL}, 1.0 \mathrm{~mol} / \mathrm{L})$ at $80^{\circ} \mathrm{C}$ for $24 \mathrm{~h}$. The yield of PA-3 was $242.3 \mathrm{~g}(65 \%)$. The $M_{\mathrm{n}}$ of PA-3 determined by GPC was $8100\left(M_{\mathrm{w}} / M_{\mathrm{n}}=1.32\right)$. IR (film, $\left.\mathrm{cm}^{-1}\right)$ : $3245(\nu \mathrm{O}-\mathrm{H}), 2978,2872(\nu \mathrm{C}-\mathrm{H})$, 1610, $1511(\nu \mathrm{C}=\mathrm{C}$, aromatic), 1244, $1174(\nu \mathrm{C}-\mathrm{F})$, 1207, 1134, 1115, 1080 (vC-O-C, acetal). ${ }^{1} \mathrm{H}$ NMR $\left(500 \mathrm{MHz}, \mathrm{DMSO}-d_{6}, \mathrm{TMS}\right): \delta 1.67(\mathrm{~d}, J=5.0 \mathrm{~Hz}$, $\left.3.0 \mathrm{H}, \mathrm{CH}_{3}\right), 6.00-6.02(\mathrm{~m}, 1.0 \mathrm{H}, \mathrm{CH}), 6.97(\mathrm{~d}$, $J=9.0 \mathrm{~Hz}, 4.0 \mathrm{H}$, aromatic $\mathrm{H}), 7.30(\mathrm{~d}, J=9.0 \mathrm{~Hz}$, $4.0 \mathrm{H}$, aromatic $\mathrm{H}) .{ }^{19} \mathrm{~F} \mathrm{NMR}\left(470 \mathrm{MHz}\right.$, DMSO- $d_{6}$, $\left.\mathrm{C}_{6} \mathrm{~F}_{6}\right): \delta-62.9$ to $-62.8\left(\mathrm{~m}, \mathrm{CF}_{3}\right)$.

Typical Procedure for Photoinduced Depolymerization of Fluorine-containing Poly(acetal)s

PA-1 (50 mg) and DPSP (2.5 mg) were dissolved in chloroform. The solution was cast on a $\mathrm{KBr}$ plate and dried to make a polymer film on the plate. The polymer film containing $5 \mathrm{wt} \%$ of a photo-acid generator (PAG) on the plate was irradiated by a $250-\mathrm{W}$ highpressure mercury lamp (Ushio Inc. USH-250D) without a filter. The intensity of the light was kept at $15 \mathrm{~mW} / \mathrm{cm}^{2}$ (at $360 \mathrm{~nm}$ ). The rate of decrease of the C-O-C stretching at $1115 \mathrm{~cm}^{-1}$ as a result of the acetal bond in main chain was measured by Fourier transform infrared spectroscopy.

\section{RESULTS AND DISCUSSION}

Fluorine-containing divinyl ether compounds, BPAFVE was synthesized in $32 \%$ yield by the reaction of BPAF with 1,2-dibromoethane follow by the dehydrohalogenation reaction using $t$-BuOK as a catalyst (Scheme 1).

The effect of the catalyst concentration on the polyaddition of BPAF with EGDVE was examined using PTS as a catalyst in THF at room temperature for $24 \mathrm{~h}$ (Scheme 2). When the reaction was carried out using $1 \mathrm{~mol} \%$ of the catalyst, the yield of the resulting polymer was $59 \%$, and $M_{\mathrm{n}}$ was 3500 . As shown in Figure 1, the yields and $M_{\mathrm{n}}$ 's of resulting polymer gradually decreased with the PTS concentration. This result shows that acetal bond of resulting polymer decomposed gradually with increasing the PTS concentration. The structure of PA-1 was confirmed by IR, ${ }^{1} \mathrm{H}$ NMR, and ${ }^{19} \mathrm{~F}$ NMR spectra.

The effect of reaction time on the polyaddition of BPAF with EGDVE was investigated using $1 \mathrm{~mol} \%$ of PTS in THF at room temperature. As shown in Figure 2 , the yields and $M_{\mathrm{n}}$ 's of resulting polymer increased until $24 \mathrm{~h}$ with reaction time. However, the

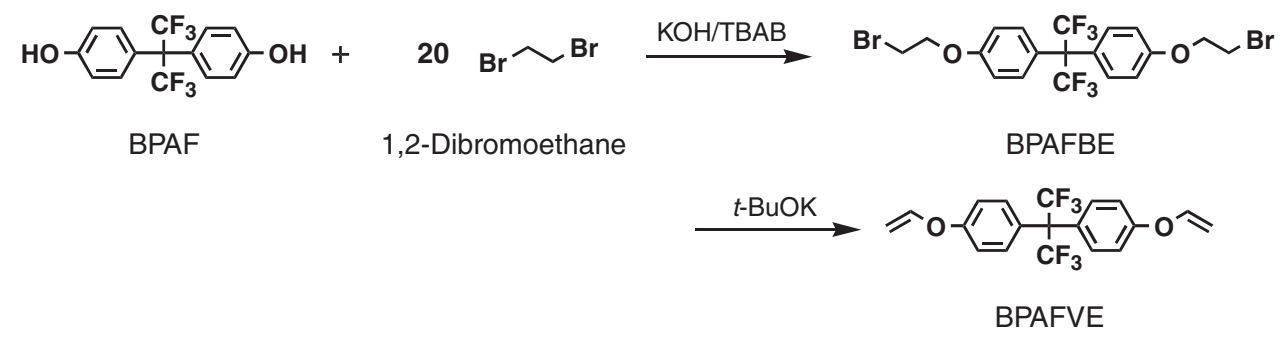

Scheme 1.
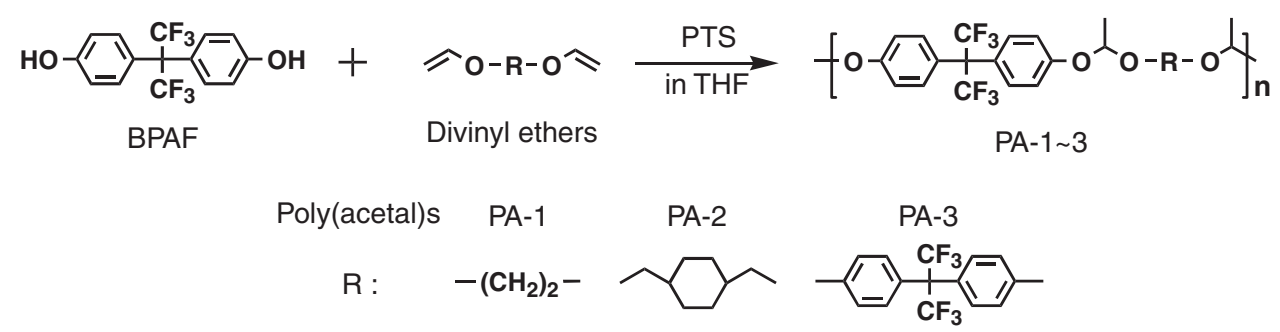

Scheme 2. 


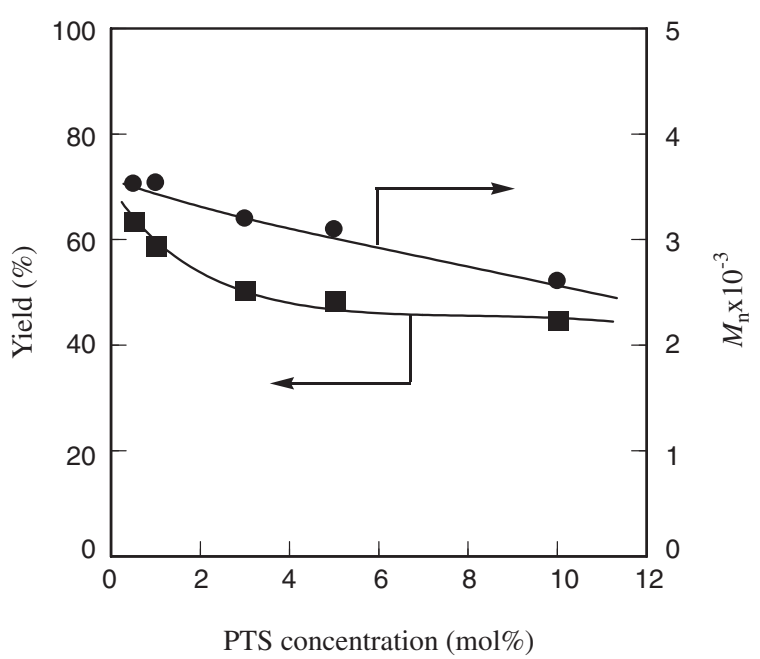

Figure 1. Effect of PTS concentration on the polyaddition of BPAF $(0.5 \mathrm{mmol})$ with EGDVE $(0.5 \mathrm{mmol})$ using PTS in THF $(1 \mathrm{~mol} / \mathrm{L})$ at room temperature for $24 \mathrm{~h}$ : $(\bullet) M_{\mathrm{n}}$; (口) yield.

yields and $M_{\mathrm{n}}$ 's of the resulting polymer decreased after $24 \mathrm{~h}$. It seems that the decomposition of the polymer occurred as a side reaction during long reaction time, although the polyaddition proceed smoothly until at $24 \mathrm{~h}$.

The effect of the reaction temperature on the polyaddition was also examined using $1 \mathrm{~mol} \%$ of PTS in THF for $24 \mathrm{~h}$. As shown in Table I, the yield and the $M_{\mathrm{n}}$ 's of the resulting polymer increased with reaction temperature, and the polymer with $M_{\mathrm{n}}=4000$ was obtained in $70 \%$ yield, when the polyaddition was performed at $50^{\circ} \mathrm{C}$.

Table I. Effect of reaction temperature on the polyaddition of BPAF with EGDE ${ }^{a}$

\begin{tabular}{ccccc}
\hline No. & Temp. $/{ }^{\circ} \mathrm{C}$ & Yield $^{\mathrm{b}} / \%$ & $M_{\mathrm{n}} \times 10^{-3 \mathrm{c}}$ & $M_{\mathrm{w}} / W_{\mathrm{n}}{ }^{\mathrm{c}}$ \\
\hline 1 & r.t. & 59 & 3.54 & 2.19 \\
2 & 50 & 70 & 4.04 & 1.99 \\
\hline
\end{tabular}

${ }^{\mathrm{a}}$ The reaction was carried out with BPAF $(0.5 \mathrm{mmol})$ and EGDE $(0.5 \mathrm{mmol})$ using PTS $(1 \mathrm{~mol} \%)$ in THF $(1 \mathrm{~mol} / \mathrm{L})$ for $24 \mathrm{~h}$. ${ }^{\mathrm{b}}$ Insoluble parts in $n$-hexane. ${ }^{\mathrm{c}}$ Estimated by GPC (THF) based on polystyrene standards.

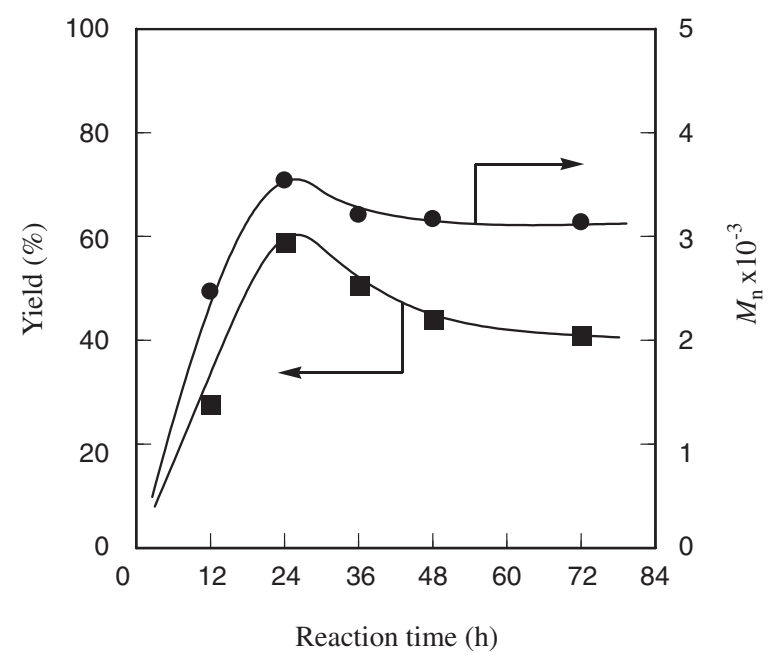

Figure 2. Effect of reaction time on the polyaddition of BPAF $(0.5 \mathrm{mmol})$ with EGDVE $(0.5 \mathrm{mmol})$ using PTS $(1 \mathrm{~mol} \%)$ in THF at room temperature: $(\bullet) M_{\mathrm{n}} ;(\mathbf{\square})$ yield.

Furthermore, the polyaddition of BPAF with certain divinyl ether compounds using $1 \mathrm{~mol} \%$ of PTS in THF was examined, and the results are summarized in Table II. PA-2 with $M_{\mathrm{n}}=8400$ was obtained in $60 \%$ yield by the polyaddition of BPAF with HMDVE at room temperature for $24 \mathrm{~h}$. Although the reaction of BAPFVE with BPAF did not proceed at room temperature, PA-3 was obtained when the polyaddition was carried out from $50{ }^{\circ} \mathrm{C}$ to 100 . PA-3 with $M_{\mathrm{n}}=$ 8100 was synthesized in $65 \%$ yield when the reaction of BPAF with BPAFVE carried out at $80^{\circ} \mathrm{C}$ for $24 \mathrm{~h}$ (Scheme 2). This result means that polymerization proceeded smoothly by heating because the electron density of vinyl group of BPAFVE is lower than that of EGDVE and HMDVE. The structures of all resulting polymers were confirmed by IR, ${ }^{1} \mathrm{H}$ NMR, and ${ }^{19} \mathrm{~F}$ NMR spectra.

$T_{\mathrm{g}}$ 's of the resulting polymers were measured by DSC. The $T_{\mathrm{g}}$ 's of PA-1, PA-2, and PA-3 were 39, 47 , and $87^{\circ} \mathrm{C}$, respectively. This shows that poly(acetal)s (PA-3) with rigid structures in the main chain had relatively higher $T_{\mathrm{g}}$ 's than poly(acetal)s (PA-1, PA-2) with flexible alkyl groups in the main chain.

Table II. Synthesis of certain poly(acetal)s by the polyaddition of BPAF with divinyl ether compounds ${ }^{\mathrm{a}}$

\begin{tabular}{cccccc}
\hline Poly(acetal)s & Divinyl ethers & Temp. $/{ }^{\circ} \mathrm{C}$ & Yield $^{\mathrm{b}} / \%$ & $M_{\mathrm{n}} \times 10^{-3 \mathrm{c}}$ & $M_{\mathrm{w}} / W_{\mathrm{n}}{ }^{\mathrm{c}}$ \\
\hline PA-1 & EGDVE & r.t. & 59 & 3.54 & 2.19 \\
PA-2 & HMDVE & r.t. & 60 & 8.38 & 1.45 \\
PA-3 & BPAFVE & r.t. & 0 & - & - \\
PA-3 & BPAFVE & 50 & 76 & 4.61 & 1.66 \\
PA-3 & BPAFVE & 80 & 65 & 8.09 & 1.32 \\
PA-3 & BPAFVE & 100 & 63 & 6.37 & 1.36 \\
\hline
\end{tabular}

${ }^{a}$ The reaction was carried out with $\operatorname{BPAF}(0.5 \mathrm{mmol})$ with divinyl ether compounds $(0.5 \mathrm{mmol})$ using PTS $(1 \mathrm{~mol} \%)$ in THF $(1.0 \mathrm{~mol} / \mathrm{L})$ for $24 \mathrm{~h} .{ }^{\mathrm{b}}$ Insoluble parts in $n$-hexane. ${ }^{\mathrm{c}}$ Estimated by GPC (THF) based on polystyrene standards. 
Table III. Characteristics of poly(acetal)s

\begin{tabular}{cccc}
\hline poly(acetal)s & $T_{\mathrm{g}} /{ }^{\circ} \mathrm{C}^{\mathrm{a}}$ & $T_{\mathrm{d}} /{ }^{\circ} \mathrm{C}^{\mathrm{b}}$ & $\mathrm{T}$ at $157 \mathrm{~nm} / \%^{\mathrm{c}}$ \\
\hline PA-1 & 39 & 247 & 39 \\
PA-2 & 47 & 237 & 33 \\
PA-3 & 87 & 267 & \\
\hline
\end{tabular}

${ }^{\text {a }}$ Determind by DSC at a heating rate of $10^{\circ} \mathrm{C} / \mathrm{min}$ in nitrogen. ${ }^{b}$ Determind by TG/DTA at a heating rate of $10^{\circ} \mathrm{C} / \mathrm{min}$ in nitrogen. ${ }^{\mathrm{c}}$ Film thickness: $1000 \AA$.

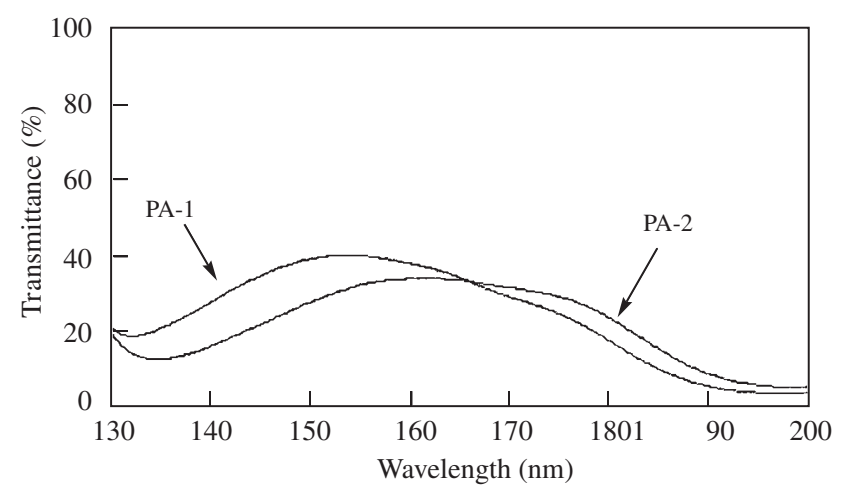

Figure 3. VUV spectra of poly(acetal)s (film thickness: $1000 \AA$ ).

The transmittances of resulting polymers were measured by VUV spectra. Transmittance at $157 \mathrm{~nm}$ and VUV spectra of resulting polymers are shown in Table III and Figure 3. It was found that these poly(acetal)s are transparent at $157 \mathrm{~nm}$ for $0.1 \mu \mathrm{m}$ thickness, and transmittance of PA- 1 and 2 were 39 and $33 \%$, respectively.

The solubility of the resulting polymers was summarized in Table IV. All of the obtained polymers were soluble in all solvents excepting $n$-hexane. It seems that the obtained fluoropolymers had good solubility.

The photoinduced depolymerization of poly(acetal)s was examined using DPSP as PAG (5 wt \%) on photo-irradiation with a $250-\mathrm{W}$ high-pressure mercury lamp in the film state (Scheme 4). As shown in Figure 4, the conversion of depolymerization in PA1 was estimated from the decreases of the absorption
Table IV. Solubility of fluorine-containing poly(acetal)s $\mathrm{s}^{\mathrm{a}}$

\begin{tabular}{lccc}
\hline \multicolumn{1}{c}{ Solvent } & PA-1 & PA-2 & PA-3 \\
\hline$n$-Hexane & - & - & - \\
Methanol & +- & +- & - \\
Acetonitrile & ++ & - & - \\
Acetone & ++ & ++ & ++ \\
Ethyl acetate & ++ & ++ & ++ \\
Chloroform & ++ & ++ & ++ \\
Toluene & ++ & ++ & ++ \\
Anisole & ++ & ++ & ++ \\
$o$-Dichlorobenzene & ++ & ++ & ++ \\
THF & ++ & ++ & ++ \\
DMF & ++ & ++ & ++ \\
NMP & ++ & ++ & ++ \\
DMSO & ++ & + & - \\
\hline
\end{tabular}

${ }^{\mathrm{a}}++$ : soluble at room temperature, + : soluble by heating, +-: partially solubleor swelling, - : insoluble.

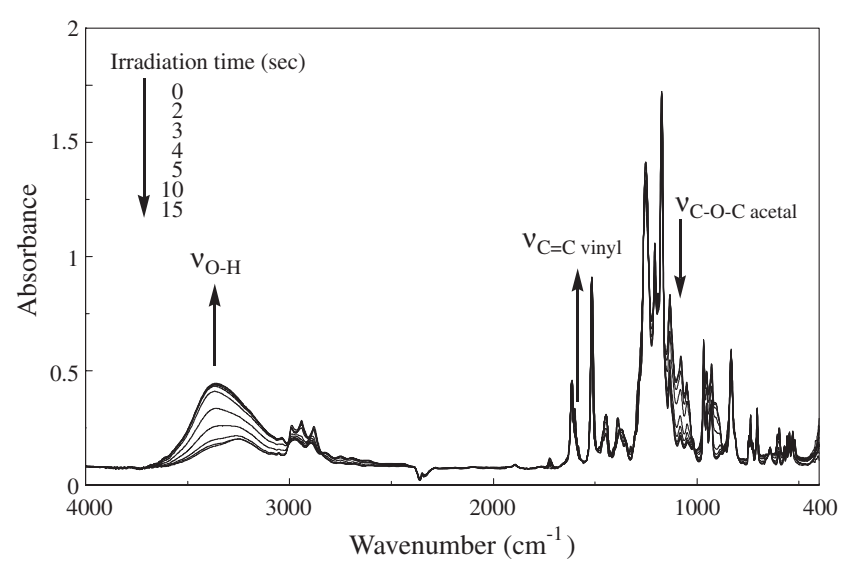

Figure 4. Change of IR spectra on the photoinduced depolymerization of PA-1 in the presence of DPSP (5 wt \%) under UV irradiation $\left(15 \mathrm{~mW} / \mathrm{cm}^{2}\right.$ at $\left.365 \mathrm{~nm}\right)$.

peaks due to the $\mathrm{C}-\mathrm{O}-\mathrm{C}$ stretching at $1115 \mathrm{~cm}^{-1}$ in the IR spectra. As shown in Figure 5, depolymerization of PA-1 and PA-2 with $5 \mathrm{~mol} \%$ of DPSP proceeded only by the photo-irradiation in the film state. On the other hand, the depolymerization of PA-3 with $5 \mathrm{wt} \%$ of DPSP did not occur only by the photo-irradiation in the film state. However, when the reaction

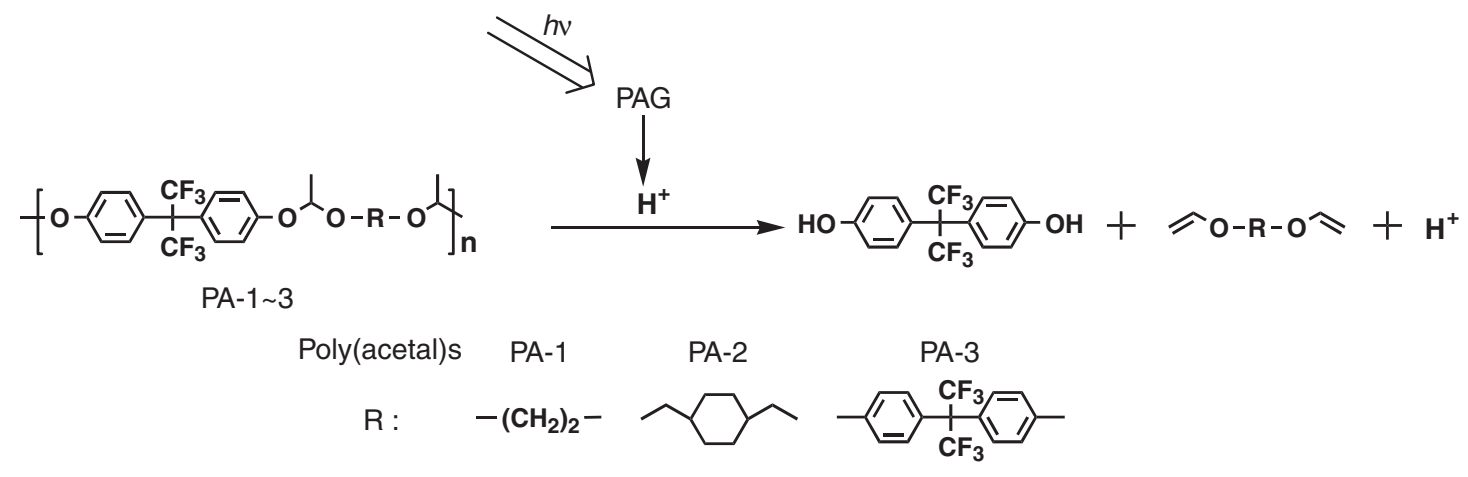

Scheme 3. 


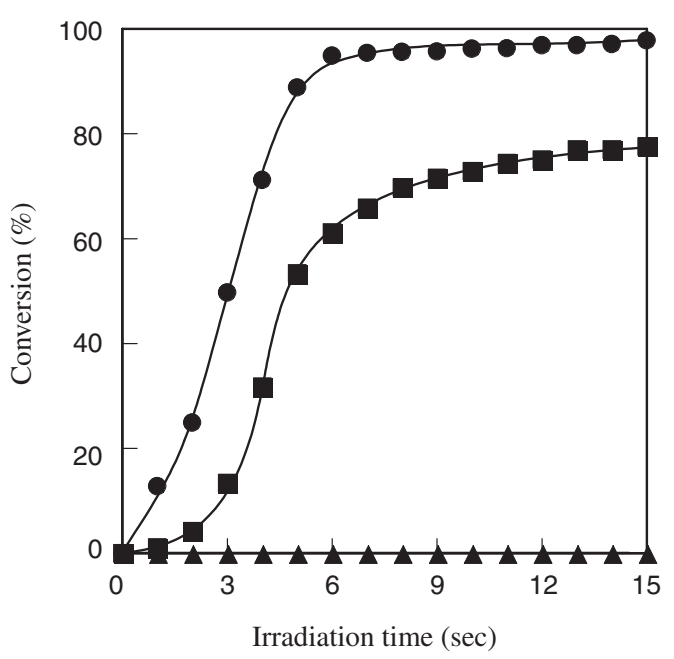

Figure 5. Effect of irradiation time on the photoinduced depolymerization of poly(acetal)s film in the presence of DPSP (5 wt \%) under UV irradiation $\left(15 \mathrm{~mW} / \mathrm{cm}^{2}\right.$ at $\left.365 \mathrm{~nm}\right)$ : (ם) PA1; (๑) PA-2; (ム) PA-3.

of PA-3 was carried out with 5 wt $\%$ of DPSP on photo-irradiation followed by heating for $1 \mathrm{~h}$ at certain temperature such as 50,100 , and $150{ }^{\circ} \mathrm{C}$, it was found that depolymerization at each temperature occurred smoothly. As the result, absorption peaks resulting from $\mathrm{C}-\mathrm{O}-\mathrm{C}$ stretching at $1115 \mathrm{~cm}^{-1}$ in the IR spectra decreased, and absorption peaks resulting $\mathrm{O}-\mathrm{H}$ stretching at around $3500 \mathrm{~cm}^{-1}$ increased. As shown in Figure 6, the conversion of depolymerization increased with heating temperature, the conversion reached about $60 \%$ by heating at $150{ }^{\circ} \mathrm{C}$. This result is explained by the following two reasons. An important reason is $T_{\mathrm{g}}$ of polymers. It seems that depolymerization occurred smoothly by heating at high temperature, because the diffusion of generated acid in the PA-3 film with high $T_{\mathrm{g}}$ than PA-1 and PA-2 would be not effective at room temperature. Another one is stability of acetal bond. It is considered that the reaction did not enough proceed because acetal bond of PA-3 is more stable than that of PA-1 and PA-2. This result suggests that electron density of acetal groups of PA-3 is low as well as vinyl group of BPAFVE.

\section{CONCLUSIONS}

The polyaddition of BPAF with divinyl ether compounds proceeds using PTS as a catalyst to produce the corresponding fluoropolymers with acetal bond in the main chains. The transmittance of fluorine-containing poly(acetal)s, PA-1 and PA-2 were 39 and $33 \%$, respectively, which are good transparent at $157 \mathrm{~nm}$. Furthermore, the photoinduced depolymerization of poly(acetal)s was examined using PAG on photo-irradiation. It was found that the depolymeriza-

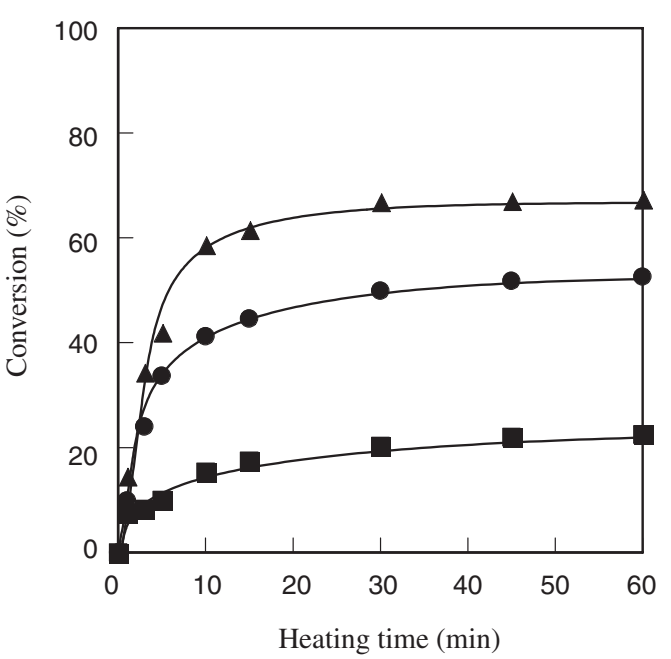

Figure 6. Effect of heating time on the photoinduced depolymerization of PA-3 film in the presence of DPSP ( $5 \mathrm{wt} \%$ ) under

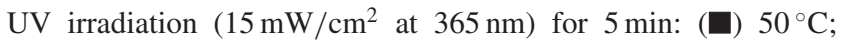
(•) $100^{\circ} \mathrm{C} ;(\boldsymbol{\Delta}) 150{ }^{\circ} \mathrm{C}$.

tion of PA-1 and PA-2 proceeded only by the photoirradiation. On the other hand, PA-3 was depolymerized by the photo-irradiation followed by heating.

Acknowledgment. The authors would like to thank Dr. T. Shimokawa and Mr. H. Iwasawa of JSR Corporation, Japan for VUV measurement.

\section{REFERENCES}

1. C. G. Willson, B. C. Trinque, B. P. Osborn, C. R. Chambers, Y. Hsieh, T. Chiba, P. Zimmerman, D. Miller, and W. Conley, J. Photopolym. Sci. Technol., 15, 583 (2002).

2. a) Y. C. Bae, K. Douki, T. Yu, J. Dai, D. Schmaljohann, S. H. Kang, K. H. Kim, H. Koerner, W. Conley, D. Miller, R. Balasubramanian, S. Holl, and C. K. Ober, J. Photopolym. Sci. Technol., 14, 613 (2001).

b) C. K. Ober, K. Douki, V. R. Vohra, Y. Kwark, X. Liu, W. Conley, D. Miller, and P. Zimmerman, J. Photopolym. Sci. Technol., 15, 603 (2002).

3. W. Conley, D. Miller, C. Chambers, B. C. Trinque, B. Osborn, T. Chiba, P. Zimmerman, R. Dammel, A. Romano, and C. G. Willson, J. Photopolym. Sci. Technol., 15, 613 (2002).

4. a) M. Shirai, T. Shinozuka, H. Okamura, M. Tsunooka, S. Kishimura, M. Endo, and M. Sasago, J. Photopolym. Sci. Technol., 14, 621 (2001).

b) S. Kishimura, M. Endo, and M. Sasago, J. Photopolym. Sci. Technol., 15, 625 (2002).

5. T. Fujigaya, S. Ando, Y. Shibasaki, S. Kishimura, M. Endo, S. Sasago, and M. Ueda, J. Photopolym. Sci. Technol., 15, 643 (2002).

6. H. Ito, G. M. Wallraff, N. Fender, P. J. Brock, C. E. Larson, H. D. Truong, G. Breyta, D. C. Miller, M. H. Sherwood, and R. D. Allen, J. Photopolym. Sci. Technol., 14, 583 (2001). 
7. T. Chiba, R. J. Hung, S. Yamada, B. Trinque, M. Yamachika, C. Brodsky, K. Patterson, A. V. Heyden, A. Jamison, S. Lin, M. Somervell, J. Byers, W. Conley, and C. G. Willson, J. Photopolym. Sci. Technol., 13, 657 (2000).

8. E. Ruckenstein and H. M. Zhang, J. Polym. Sci., Part A:
Polym. Chem., 38, 1848 (2000).

9. Y. Konno, H. Kudo, A. Kameyama, and T. Nishikubo, J. Polym. Sci., Part A: Polym. Chem., in press.

10. Y. Konno, H. Suzuki, H. Kudo, A. Kameyama, and T. Nishikubo, Polym. J., 36, 114 (2004). 